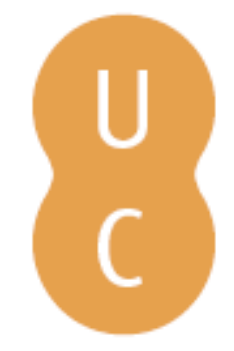

\title{
nommalina
}

\section{Imaginando o combatente ideal do PAIGC: a construção dos heróis nacionais na imprensa do pós-independência na Guiné-Bissau e em Cabo Verde}

\author{
Autor(es): $\quad$ Coutinho, Ângela Sofia Benoliel
}

Publicado por: Imprensa da Universidade de Coimbra

URL

persistente: URI:http://hdl.handle.net/10316.2/32162

DOI: $\quad$ DOI:http://dx.doi.org/10.14195/978-989-26-0339-1_13

Accessed : $\quad$ 26-Apr-2023 06:50:54

A navegação consulta e descarregamento dos títulos inseridos nas Bibliotecas Digitais UC Digitalis, UC Pombalina e UC Impactum, pressupõem a aceitação plena e sem reservas dos Termos e Condições de Uso destas Bibliotecas Digitais, disponíveis em https://digitalis.uc.pt/pt-pt/termos.

Conforme exposto nos referidos Termos e Condições de Uso, o descarregamento de títulos de acesso restrito requer uma licença válida de autorização devendo o utilizador aceder ao(s) documento(s) a partir de um endereço de IP da instituição detentora da supramencionada licença.

Ao utilizador é apenas permitido o descarregamento para uso pessoal, pelo que o emprego do(s) título(s) descarregado(s) para outro fim, designadamente comercial, carece de autorização do respetivo autor ou editor da obra.

Na medida em que todas as obras da UC Digitalis se encontram protegidas pelo Código do Direito de Autor e Direitos Conexos e demais legislação aplicável, toda a cópia, parcial ou total, deste documento, nos casos em que é legalmente admitida, deverá conter ou fazer-se acompanhar por este aviso.

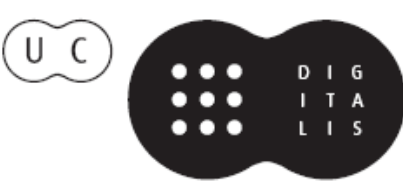




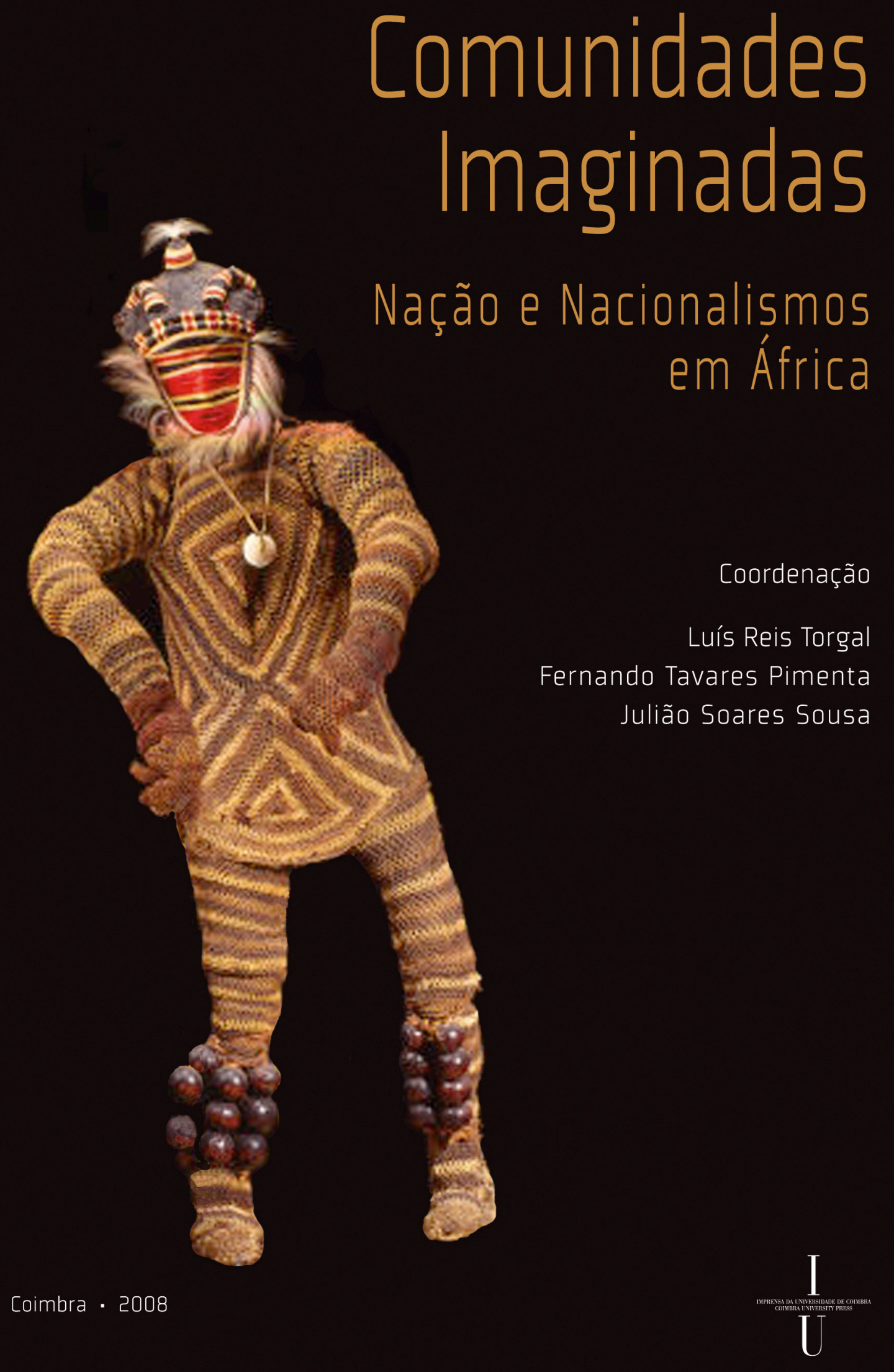




\title{
Comunidades Imaginadas \\ Nação e Nacionalismos em África
}

\author{
Coordenação \\ Luís Reis Torgal \\ Fernando Tavares Pimenta \\ Julião Soares Sousa
}

Coimbra $\cdot 2008$

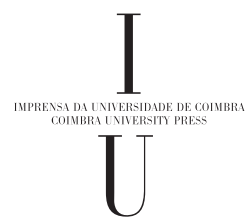




\begin{abstract}
COORDENAÇÃO EDITORIAL
Imprensa da Universidade de Coimbra

Email: imprensauc@ci.uc.pt

URL: http://www.uc.pt/imprensa_uc
\end{abstract}

CONCEPÇÃO GRÁFICA

António Barros

PAGINACÁO

Paulo Oliveira

[PMP]

EXECUÇÃO GRÁFICA

?????????????

ISBN

978-989-8074-57-7

DEPÓSITO LEGAL

????????????????????????

OBRA PUBLICADA COM A COLABORAÇÃO DE:

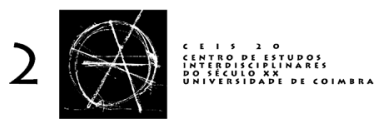

OBRA PUBLICADA COM O APOIO DE:

FCT Fundação para a Ciência e a Tecnologia

MINISTÉRIO DA CIÊNCIA, TECNOLOGIA E ENSINO SUPERIOR Portugal

Apoio do Programa Operacional Ciência, Tecnologia, Inovação do Quadro Comunitário de Apoio III 



\section{Ângela Sofia Benoliel Coutinho}

\section{IMAGINANDO O COMBATENTE IDEAL DO PAIGC A CONSTRUÇÃO DOS HERÓIS NACIONAIS NA IMPRENSA DO PÓS-INDEPENDÊNCIA NA Guiné-BisSAu E EM CABo Verde}

Através deste estudo, procuraremos analisar a imagem que se criou dos heróis nacionais proclamados pelo PAIGC, na Guiné-Bissau e em Cabo Verde, no pósindependência. Sendo que estes dois países independentes viveram um sistema de partido único de 1975 a 1980, tratando-se do mesmo partido em ambos os países, tentaremos identificar estes heróis recorrendo à imprensa escrita durante esse período, até ao ano de 1980, o ano de cisão do PAIGC. Interessar-nos-á em particular identificar os valores defendidos na apresentação e descrição destes heróis.

Consultámos o periódico guineense Nô Pintcha e o cabo-verdiano Voz di Povo, os únicos órgãos oficiais de imprensa escrita de publicação regular, de 1975 até $1980 \mathrm{em}$ cada um dos países, de forma a analisar o modo como eram apresentados estes heróis nacionais. Decidimos estudar unicamente os que foram apresentados como heróis com mais frequência, durante o período em apreço.

Elaborámos, assim, uma lista de seis indivíduos: Amílcar Cabral, Francisco Mendes, Pansau Na Isna, Domingos Ramos, Titina Silá e Osvaldo Vieira. Elaborámos também uma tabela com informaçóes sobre os respectivos locais e datas de nascimento, profissão, carreira no PAIGC e no aparelho de Estado.

\section{Combatentes guineenses ou o heroísmo nacional quase exclusivo}

Tabela 1 - Características dos heróis

\begin{tabular}{|l|l|l|l|l|l|}
\hline Nomes & $\begin{array}{l}\text { Locais de } \\
\text { nascimento }\end{array}$ & $\begin{array}{l}\text { Anos de } \\
\text { nascimento }\end{array}$ & Profissão & $\begin{array}{l}\text { Carreira no } \\
\text { PAIGC }\end{array}$ & $\begin{array}{l}\text { Carreira } \\
\text { no Estado }\end{array}$ \\
\hline $\begin{array}{l}\text { Cabral, } \\
\text { Amílcar }\end{array}$ & Bafatá - GB & 1924 & $\begin{array}{l}\text { Engenheiro } \\
\text { Agrónomo }\end{array}$ & $\begin{array}{l}\text { fundador } \\
\text { e membro } \\
\text { da } \\
\text { Comissão } \\
\text { Permanente }\end{array}$ & $\begin{array}{l}\text { Falecido em } \\
1973\end{array}$ \\
\hline $\begin{array}{l}\text { Mendes, } \\
\text { Francisco }\end{array}$ & $\begin{array}{l}\text { Enxudé, } \\
\text { Buba - GB }\end{array}$ & 1939 & $\begin{array}{l}\text { Empregado } \\
\text { na } \\
\text { Granja do } \\
\text { Pessubé }\end{array}$ & $\begin{array}{l}\text { Membro da } \\
\text { Comissáo } \\
\text { Permanente }\end{array}$ & $\begin{array}{l}\text { Primeiro- } \\
\text { Finistro - GB } \\
1978\end{array}$ \\
\hline
\end{tabular}




\begin{tabular}{|l|l|l|l|l|l|}
\hline $\begin{array}{l}\text { Na Isna, } \\
\text { Pansau }\end{array}$ & $\begin{array}{l}\text { Ilhéu de } \\
\text { N'Fanda - GB }\end{array}$ & Camponês & Combatente & $\begin{array}{l}\text { Falecido } \\
\text { antes de 1973 }\end{array}$ \\
\hline $\begin{array}{l}\text { Ramos, } \\
\text { Domingos }\end{array}$ & Bissau - GB & 1935 & $\begin{array}{l}\text { Trabalhou na } \\
\text { área da } \\
\text { Saúde }\end{array}$ & $\begin{array}{l}\text { Membro do } \\
\text { Bureau } \\
\text { Político }\end{array}$ & $\begin{array}{l}\text { Falecido em } \\
1966\end{array}$ \\
\hline Silá, Titina & Tombali - GB & 1943 & $\begin{array}{l}\text { sem } \\
\text { profissão }\end{array}$ & $\begin{array}{l}\text { Membro do } \\
\text { CSL }\end{array}$ & $\begin{array}{l}\text { Falecida em } \\
1973\end{array}$ \\
\hline $\begin{array}{l}\text { Vieira, } \\
\text { Osvaldo }\end{array}$ & Bissau - GB & 1939 & $\begin{array}{l}\text { Cobrador } \\
\text { numa } \\
\text { farmácia }\end{array}$ & $\begin{array}{l}\text { Membro do } \\
\text { CSL }\end{array}$ & $\begin{array}{l}\text { Falecido em } \\
1974\end{array}$ \\
\hline
\end{tabular}

Fontes: Nô Pintcha

CLS : Conselho Superior da luta

Notamos, em primeiro lugar, que todos os heróis nasceram na Guiné-Bissau. Este dado pode parecer estranho, sendo que o partido era bi-nacional. Apesar de termos constatado que a maioria dos dirigentes do PAIGC eram naturais da Guiné ${ }^{1}$, e sabendo que o conflito armado decorreu em território guineense, envolvendo a população, o PAIGC teve também, obviamente, dirigentes naturais de Cabo Verde e contou, nas suas fileiras, com guerrilheiros cabo-verdianos, sobretudo a partir de $1968^{2}$. Terá interesse aprofundar a compreensão deste facto, sobretudo tendo em conta o contributo que terá tido na construção de um imaginário colectivo na altura. É também necessário notar que, à excepção de Amílcar Cabral, nenhum outro herói surge nas páginas do jornal cabo-verdiano Voz di Povo. Ora, sendo a proclamação feita pelo partido, é estranho que o jornal cabo-verdiano não tivesse apresentado igualmente os outros heróis.

Também pudemos constatar que a maioria destes heróis nasceu na década de 1930, tendo Amílcar Cabral nascido em 1924 e Titina Silá em 1943. Todos, à excepção de Pansau Na Isna assumiram funçóes de direcção política no partido e um único, Francisco Mendes, assumiu responsabilidades a nível do governo da Guiné-Bissau. De salientar igualmente a presença de uma mulher entre estes heróis, ou seja, Titina Silá.

A maioria dos heróis faleceu em tempo e terreno de guerra, e portanto antes da independência. Apenas Francisco Mendes faleceu na sequência de um acidente de viação alguns anos após a independência, mais precisamente em 1978. Era então comissário-principal, ou seja, primeiro-ministro da República da Guiné-Bissau.

Domingos Ramos faleceu num combate em Madina do Boé em 1966. Pansau Na Isna também perdeu a vida em combate antes da independência, na região de Nhacra. A 20 de Janeiro de 1973, Amílcar Cabral foi assassinado em Conakry, em frente à sua residência, por um grupo que pretendia prender e eventualmente eliminar os dirigentes do PAIGC que se encontravam então na capital da Guiné-Conakry. Alguns dias mais tarde, quando se deslocava de barco para assistir ao seu funeral, Titina Silá foi ferida por atiradores inimigos, caiu à água e morreu afogada. Quanto a Osvaldo Vieira, faleceu vítima de doença, em 1974.

\footnotetext{
${ }^{1}$ Ver tese de doutoramento de BENOLIEL COUTINHO, Ângela Sofia, Les dirigeants du PAIGC - étude de parcours individuels, de stratégies familiales et d'idéologies, Paris, Université de Paris I, 2004.

${ }^{2}$ Ver PEREIRA, Aristides, O meu testemunho - uma luta, um partido, dois países - versão documentada, Lisboa, Notícias, 2003.
} 
Amílcar Cabral não somente é o único herói cujo retrato foi apresentado no periódico cabo-verdiano, mas, no periódico guineense, a sua imagem foi tratada de forma diferente em relação aos outros, por isso decidimos analisar o seu caso separadamente e não será exposto aqui.

Iremos, portanto, tratar da imagem dos heróis surgidos no jornal Nô Pintcha.

\section{Combatentes dedicados lutando pela liberdade e pelo progresso}

Agrupámos assim os artigos respeitantes a todos e em seguida, cruzámos todas as qualidades postas em evidência, de forma a identificar as mais frequentes. Aquela em relaçáo à qual havia mais insistência era a devoçáo ou a abnegaçáo. Insistiu-se sobre o facto destes heróis terem sacrificado as suas vidas ou de se terem dedicado sem limites à causa da liberdade. A morte em terreno de guerra era a primeira etapa e a mais importante para se tornar um herói; a devoçáo é por isso entendida como o sacrifício da vida. Vejamos alguns exemplos concretos de acçôes levadas a cabo pelos heróis neste sentido.

O exemplo mais evidente é o de Titina Silá, de quem se diz que foi :

[...] a mulher que não poupou sacrifícios para a libertação total e completa do nosso povo, dando tudo o que possuía, até a sua vida para que o nosso povo gozasse hoje a paz e a felicidade. ${ }^{3}$

Esta qualidade surge várias vezes nos artigos que lhe são dedicados. Diz-se também dela :

Na sua acção como militante do Partido nunca se poupou a sacrifícios para cumprir até ao fim todas as suas missões. ${ }^{4}$

E também:

Demonstrando a sua grande dedicaçáo e confiança no Partido, Titina foi a primeira a ser escolhida. ${ }^{5}$

Enfim,

Com o seu trabalho, a sua dedicação sem limites ao Partido, a camarada Titina teve naquele tempo um papel importante na mobilizaçáo e no encorajamento de outros militantes e da população daquela área. ${ }^{6}$

\footnotetext{
${ }^{3}$ Nô Pintcha, 01/02/1977, p. 4.

${ }^{4}$ Nô Pintcha, idem, ibidem.

${ }^{5}$ Nô Pintcha, idem, ibidem.

${ }^{6}$ Nô Pintcha, idem, ibidem.
} 
Titina Silá é sem dúvida a heroína mais marcada por esta qualidade. Será por se tratar de uma mulher? Terá havido uma aproximação à imagem da mulher-mãe que tudo faz pelos seus filhos ? Titina Silá teve dois filhos. Seria muito interessante fazer uma análise da aproximação quase automática da imagem da mulher à de mãe, ainda que tratando-se de uma guerrilheira.

Outros heróis foram apresentados como tendo-se dedicado à causa da liberdade. Foi o caso de Domingos Ramos e de Francisco Mendes. Assim, diz-se do primeiro que ele "[...] dedicou-se activamente à luta pela libertaçáo da Pátria.»" e que ele " [...] sacrificou assim a sua vida. ${ }^{8}$. Evocando a sua acção, no artigo afirma-se:

As dificuldades atingiam considerável amplitude mas Domingos e os seus camaradas souberam superá-las, com sacrifício e abnegação. ${ }^{9}$

Ou ainda:

[...] figuras que, pela sua coragem, militância e dedicação, revelam tudo quanto um verdadeiro filho deve ser para com o seu povo e para com a sua pátria. ${ }^{10}$

Tal como para Titina Silá, esta qualidade é por vezes enunciada quando se descreve uma acção considerada de valor.

A segunda qualidade mais citada é a de combatente. Assim, surgem referências a Domingos Ramos como «combatente da liberdade » e " combatente infatigável ». Osvaldo Vieira é apresentado como sendo um " grande combatente» e Titina Silá como "mulher combatente» e "combatente corajosa ». Não é o caso de Francisco Mendes, talvez por o seu falecimento ter surgido num momento em que ele era mais conhecido pelas funções que exercia no aparelho de Estado. Curiosamente, Pansau $\mathrm{Na}$ Isna também não é qualificado de combatente, já que este termo faz referência de forma directa ao combate propriamente dito, ou seja, às situaçóes de guerra nas quais os heróis se evidenciaram.

A terceira qualidade mais referida é a de se ser estimado pela colectividade e a de se ser considerado como exemplar. Ser estimado pela colectividade, como Domingos Ramos por exemplo, é gozar de uma "[...] enorme admiração que por ele tinham todos os combatentes." 11 e de "[...] muita simpatia entre os militantes e no seio do nosso povo." 12 e isto sobretudo porque se dá provas de solidariedade:

[...] infatigável combatente da nossa causa cuja conduta e humanismo o fizeram dos mais amados entre os seus camaradas de luta, com os quais em muitas circunstâncias se prontificava a dividir a sua ração, $\left[\ldots . . .{ }^{13}\right.$

\footnotetext{
${ }^{7}$ Nô Pintcha, 20/01/76, p. 4.

${ }^{8}$ Nô Pintcha, 20/01/79, p. 5.

${ }^{9}$ Nô Pintcha, 20/01/76, p. 8.

${ }^{10}$ Nô Pintcha, 20/01/79, p.5.

${ }^{11}$ Nô Pintcha, 20/01/76, p. 4.

${ }^{12}$ Nô Pintcha, 20/01/76, p. 8.

${ }^{13}$ Nô Pintcha, 20/01/79, p. 5.
} 
E também:

Domigos amava profundamente os combatentes, queria-lhes como irmãos. Nos momentos difíceis repartia as suas roupas e provisóes com os combatentes. Sempre que se tornava necessário matar a fome com frutos silvestres, era o primeiro a experimentá-los não permitindo que os seus camaradas os comessem antes desse exame. Por mais cansado que se sentisse depois das longas marchas, utilizava as altas de repouso para ajudar os combatentes a obter os conhecimentos de base. ${ }^{14}$

É portanto também saber estar atento às dificuldades enfrentadas pelos outros, qualidade muito importante para a vida comunitária. Esta capacidade também é atribuída a Titina Silá, ao afirmar-se que ela ajudava os seus camaradas de turma quando seguia formaçóes no estrangeiro. ${ }^{15}$

Quanto ao carácter exemplar das acçóes de todos estes militantes, é uma qualidade que surge com frequência. É um atributo perfeitamente pertinente tratando-se de um herói. Francisco Mendes é considerado como "um alto exemplo de militância e de patriotismo" ${ }^{16}$, enquanto Domingos Ramos é apresentado como " um companheiro exemplar ». Afirma-se também que ele desempenhava um papel exemplar em situaçóes de combate. Quanto a Titina Silá, ela é « um exemplo da verdadeira militante do nosso partido " ${ }^{17}$. Também se afirma que " com o seu exemplo ela levou muitos camaradas a náo desmoralizar e a manter bem alto a bandeira do nosso partido " ${ }^{18}$ e que " os seus feitos [são] um exemplo válido para a continuação da luta pelo progresso do nosso povo. " ${ }^{19} \mathrm{O}$ seu carácter exemplar estende-se mais além, porque ela é considerada não somente como um "exemplo de combatente corajosa» ${ }^{20}$ mas também como um " exemplo de mulher africana» ${ }^{21}$.

A quarta qualidade mais apreciada é a coragem. Assim, considera-se Francisco Mendes como sendo "um dos combatentes mais corajosos» 22. Em relação a Pansau $\mathrm{Na}$ Isna, conta-se que a sua coragem foi determinante na conquista militar da regiáo sob o seu comando. Domingos Ramos é apresentado como bravo e indomável nos combates.

Há também referências aos heróis como militantes. É de assinalar, no entanto, que o termo combatente é de uso mais frequente nas descriçôes que o de militante, o que nos permite afirmar, tendo em conta a conotação do termo, que se valorizava mais a imagem do guerreiro e a actividade militar propriamente dita. Ora, vimos que

\footnotetext{
${ }^{14}$ Nô Pintcha, 20/01/76, p. 8.

${ }^{15}$ Nô Pintcha, 20/01/76, p. 5.

${ }^{16}$ Nô Pintcha, 08/07/78, p. 8.

${ }^{17}$ Nô Pintcha, 01/02/77, p. 4.

${ }^{18}$ Nô Pintcha, idem, ibidem.

${ }^{19}$ Nô Pintcha, 20/01/79, p. 5.

${ }^{20}$ Nô Pintcha, 01/02/77, p. 4.

${ }^{21}$ Nô Pintcha, idem, ibidem.

${ }^{22}$ Nô Pintcha, 20/01/79, p. 6.
} 
os dirigentes do PAIGC também tinham assumido actividades de âmbito puramente político, social ou diplomático. Foi neste último plano que obtiveram os sucessos mais imediatos.

Enfim, uma última forma, bastante peculiar, de apresentar estes heróis era a de lhes conceder a denominação de filho. Esta ligação às relações familiares deve ser salientada, já que foram vários os que mereceram esta apelação. Francisco Mendes foi assim chamado "filho digno do povo da Guiné e de Cabo Verde " ${ }^{23}$ e até "filho de África ". Quanto a Domingos Ramos, ele revelou «tudo o que um verdadeiro filho deve ser em relação ao seu povo e à sua pátria.» ${ }^{24}$ Titina Silá, por fim, era considerada como uma filha por Amílcar Cabral.

Nós podemos concluir que estes heróis guineenses, que sacrificaram as suas vidas, eram combatentes, muito apreciados pelos seus companheiros, exemplares, corajosos, verdadeiros militantes e filhos dignos do seu povo.

Muitas outras qualidades foram referidas, mas com menos insistência, como por exemplo, a de serem dirigentes, de terem qualidades de organização, de serem dinâmicos, inteligentes. Enfim um herói devia ser capaz de orientar os outros, amar o partido sem limites, ajudar os outros e ser patriota.

Notamos também que os retratos mais aprofundados foram os de Domingos Ramos, Titina Silá e Francisco Mendes. Os de Pansau Na Isna e Osvaldo Vieira são, com efeito, muito menos detalhados.

Algumas atitudes destes heróis foram também salientadas; insistiu-se mais em relação a duas. Trata-se da capacidade de ouvir a mensagem do partido e a de recusar a cooperação com os colonialistas.

A primeira qualidade foi atribuída muito particularmente a Titina Silá. A exposição da sua capacidade de escutar e compreender esta mensagem ganha um carácter quase religioso, sobretudo quando se proclama que ela anunciava uma nova era de felicidade :

Esta mulher da nossa terra ouviu desde o início da luta a grande mensagem de libertação do nosso Partido, e percebeu que essa mensagem anunciava uma nova era de felicidade por que o nosso povo há muito esperava, debaixo da miséria e do sofrimento em que vivia. ${ }^{25}$

Por outro lado, a segunda qualidade é atribuída a Domingos Ramos. Assim, afirma-se que ele "opôs-se abertamente aos maus tratos infligidos pelos colonialistas aos seus compatriotas» ${ }^{26}$. Referindo-se ao massacre de Pidjiguiti ${ }^{27}$, relata-se o seu comportamento face a esta tragédia, a forma como ele se recusou a participar, sendo, na altura, militar português:

${ }^{23}$ Nô Pintcha, $08 / 07 / 78$, p. 8.

${ }^{24}$ Nô Pintcha, 20/01/79, p. 5.

${ }^{25}$ Nô Pintcha, 20/01/79, p. 5.

${ }^{26}$ Nô Pintcha, 20/01/76, p. 4.

${ }^{27}$ A 3 de Agosto de 1959, os trabalhadores do porto de Bissau manifestaram-se ; a polícia e o Exército intervieram, provocando cerca de cinquenta mortos e algumas centenas de feridos. Este acontecimento foi mais tarde chamado de massacre de Pidjuiguiti, o nome do porto de Bissau. 
[...], se recusou a participar na vergonhosa acção contra os marinheiros de Bissau que reclamavam a miséria do seu ordenado, abandonando o exército colonial em que fora integrado à força." 28

Por que motivos estes heróis lutaram ? Na sua apresentação, também se faz referência aos ideais pelos quais lutaram. As palavras de ordem são a liberdade, o progresso, a paz, a felicidade. Francisco Mendes "prestou serviços relevantes ao PAIGC e à causa da libertação e do progresso do nosso povo, [... ${ }^{29}$. Quanto a Titina Silá, ela " deu tudo o que tinha, até a sua vida para que o nosso povo goze hoje da paz e da felicidade.» ${ }^{30}$ Ela tinha também " [...] uma grande vontade [...] de ver o seu povo livre e independente [...]. »31

Pensamos que o aprofundamento deste estudo poderá constituir um contributo útil para se apreender o ideal de nação que o PAIGC tentou criar junto aos povos da Guiné-Bissau e de Cabo Verde e a forma como procurou fazê-lo. No entanto, será igualmente pertinente a análise destas mesmas construçôes e representações no imaginário popular, recorrendo, por exemplo, ao estudo das letras de músicas populares, estudos esses que esperamos que se possam vir a concretizar num futuro próximo.

\section{Bibliografia Geral}

AABY, Peter, The State of Guinea-Bissau : African Socialism or Socialism in Africa?, Uppsala, Scandinavian Institute of African Studies, 1978.

ANDRÉINI, Jean-Claude, LAMBERT, Marie-Claude, La Guinea-Bissau d'Amílcar Cabral à la reconstruction nationale, Paris, l'Harmattan, 1978.

CABRAL, Luís, Crónica da libertação, Lisboa, o jornal, 1984.

CASTANHEIRA, José Pedro, Quem mandou matar Amílcar Cabral ?, Lisboa, Relógio d’Água, 1995.

CHALIAND, Gérard, Lutte armée en Afrique, Paris, Maspero, 1967.

CHILCOTE, Ronald H., Amilcar Cabral's Revolutionary's Theory and Practice - a Critical Guide, Londres, Lynne Publishers, 1991.

CRIMI, Bruno, LUCAS, Uliano, Guinea-Bissau : una rivoluzione africana, Milano, Vangelista, 1970.

DAVIDSON, Basil, La liberazione della Guinea - aspetti di una rivoluzione africana, Torino, Einaudi, 1970.

DAVIDSON, Basil, Growing from grassroots : the state of $G-B$, London, Committee for Freedom in Mozambique, Angola and Guiné, 1973.

DHADA, Mustafah, Warriors at work : how Guinea was really set free, Niwot, University press of Colorado, 1993.

\footnotetext{
${ }^{28}$ Nô Pintcha, 20/01/79, p. 5.

${ }^{29}$ Nô Pintcha, $08 / 07 / 78$, p. 8.

${ }^{30}$ Nô Pintcha, 01/02/77, p. 4.

${ }^{31}$ Nô Pintcha, idem, ibidem.
} 
GALLI, Rosemary, JONES, Jocelyn, Guinea-Bissau: Politics, Economics and Society, London, Frances Pinter, 1987.

LOBBAN, Richard, FORREST, Joshua, Historical Dictionary of the Republic of Guinea-Bissau, $2^{\text {nd }}$ ed., London, The Scarecrow Press, 1988, (African Historical Dictionaries, n. ${ }^{\circ} 22$ ).

LOPES, Carlos, A transição histórica na Guiné-Bissau - do movimento de libertação nacional ao Estado, Genève, s.e., 1982.

LOPES, José Vicente, Cabo Verde - os bastidores da independência, Praia - Mindelo, Instituto Camôes - Centro Cultural Português, 1996.

PEREIRA, Aristides, O meu testemunho - uma luta, um partido, dois paises - versão documentada, Lisboa, Notícias, 2003.

PIERSON-MATHY, Paulette, La naissance de l'Etat par la guerre de libération nationale: le cas de la Guinée-Bissau, Paris, Unesco, 1980.

RUDEBECK, Lars, Guinea-Bissau - a Study of Political Mobilisation, Uppsala, Scandinavian Institute of African Studies, 1974.

RUDEBECK, Lars, Problèmes de pouvoir populaire et de développement: transition difficile en Guinée-Bissau, Uppsala, Scandinavian Institute of African Studies, 1982.

SARRAZIN, Chantal, GJORSTAD, Ole, Sowing the first harvest: national reconstruction in Guinea-Bissau, Oakland, LSM Information Center, s.d. 



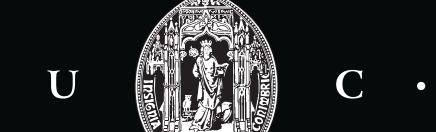

